\title{
Comparison of Two Soil Water Evaporation Models in a Sandy Soil
}

\author{
Ayman Suleiman ${ }^{1 *}$ and Brian Boman ${ }^{2}$ \\ ${ }^{1}$ Department of Land, Water and Environment, Faculty of Agriculture, The University of Jordan, Amman, Jordan \\ ${ }^{2}$ Indian River Research and Education Center, University of Florida, 2199 South Rock Road, Fort Pierce, Florida \\ ${ }^{*}$ Corresponding author: Ayman Suleiman, Department of Land, Water and Environment, Faculty of Agriculture, The University of Jordan, Amman, Jordan, Tel: \\ +9626-5322377; E-mail: ayman_suleiman_va@yahoo.com
}

Rec date: Nov 26, 2013; Acc date: May 01, 2014; Pub date: May 08, 2014

Copyright: ( 2014 Suleiman A, et al. This is an open-access article distributed under the terms of the Creative Commons Attribution License, which permits unrestricted use, distribution, and reproduction in any medium, provided the original author and source are credited.

\begin{abstract}
Modeling soil water evaporation and soil moisture are valuable for many applications in diverse disciplines. Ritchie and Snyder, presented different models to estimate soil water evaporation (ES) rate. The former also simulates the soil water dynamics at different soil depths. The objectives of this study were to evaluate the potential use of the $S 2000$ model for soils with water content above $\theta_{D U L}$ in some parts of the profile and to evaluate R2009 ES model and compare its performance with that of S2000. The study was carried out at the University of Florida Indian River Research and Education Center in Fort Pierce, Florida in 2012 and 2013. Eight Time-Domain Transmissometry (TDT) probes were installed in a lysimeter filled with sand and measured hourly soil water content for six months. Three drying cycles (cases) were used for the evaluation of the models. R2009 underestimated the soil water content near the soil surface for Case 1 and 2. While for Case 3, R2009 estimated the near surface soil water content well for the first four days and then it tended to underestimate for the rest of the days. S2000 with the proper parameterization outperformed R2009 which overestimated ES. It was evident that getting the suitable parameterization for S2000 model was not always guaranteed. These finding may only apply for sandy soils similar to the one used in this study. Future studies should be done on different soils and diverse environment before generalization can be made.
\end{abstract}

Keywords: Soil water evaporation; Soil moisture; S2000 model

\section{Introduction}

Evapotranspiration (ET) is a major component of the energy and water balances over land. Many studies of long-term averages have shown that more than half of the net solar energy and two thirds of precipitation go to ET over land [1-3]. Evaporation of water from soil surfaces (ES) is a major component in the soil water balance for field crops with incomplete cover and for bare soil conditions. Most crop, hydrology, and water quality models require the simulation of evaporation from the soil surface. Quantification of ES is necessary in evaluating the water balance of soils for use in environmental and hydrologic studies and for crop management. Water evaporation from a soil surface can be divided into two stages: (i) the constant-rate stage in which ES is limited only by the supply of energy to the surface, and (ii) the falling-rate stage in which water movement to the evaporation sites near the surface is controlled by the soil moisture conditions and soil hydraulic properties $[3,4]$.

Two basic approaches have been used to simulate ES: (i) mechanistic models of soil water and heat transfer following basic theory reported by Philip and DeVries [5], and (ii) functional models similar to that of Ritchie [4]. The mechanistic models have proven to work well for uniform laboratory soil conditions and have been demonstrated to work reasonably well for field conditions [6-10]. Functional models have also proven to work well for field conditions $[4,11,12]$ although some functional models for ES have used crude but logical approximations for soil water redistribution [13]. ES rate depends on the initial soil water content, texture and density of the soil, thermal profile of the soil, potential evaporation demand, and the depth of the evaporation layer. Some uncertainties of ES estimation may be caused by heterogeneity and spatial variability of soil hydraulic properties, tillage, soil temperature, wetting characteristics, layering, and plant root extraction of water from the evaporation layer $[14,15]$.

Suleiman and Ritchie [12] built a physically-based model for soil water redistribution during second stage evaporation using a diffusion based concept. The use of square root of time to estimate ES has been robust [16]. The initial condition of soil water content of their procedure was equal to or less than the drained upper limit $\left(\theta_{\mathrm{DUL}}\right)$ throughout the profile. When the soil water content is above $\theta_{\text {DUL }}$ in any part of the profile, the Suleiman and Ritchie [12] underestimates ES and thus do not simulate the soil water distribution accurately. An extension to Suleiman and Ritchie [12] approach, when all or part of the soil profile is above $\theta_{\mathrm{DUL}}$ such as after rainfall or irrigation or when a shallow water table exists, was done by Ritchie [1]. There is no need to adjust the time variable in these models as new precipitation or irrigation water enters the soil profile because they use the soil water content as an independent variable, not the time. Also, these models simulate the soil water dynamics during evaporation. These models were implemented in the comprehensive Decision Support System for Agro technology Transfer (DSSAT), which is the most widely used crop simulation model in the world.

Snyder [2] developed a model that uses the ratio of ES to reference evapotranspiration $\mathrm{ET}_{\mathrm{o}}$ rate $\left(\mathrm{ES} / \mathrm{ET}_{\mathrm{o}}\right.$ ) during first stage soil evaporation to estimate ES. The model uses ES/ $\mathrm{ET}_{\mathrm{o}}$ and a soil hydraulic factor, $\beta$, to estimate second stage ES. Generally, the model provides good estimates of cumulative soil evaporation on both hourly and daily basis [2]. According to Allen [17], $\beta$ changes with ET demand and needs a continuous recalibration. Ventura [18] proposed a procedure to obtain the Snyder [2] model parameters from soil moisture following large precipitation or irrigation events, found that 
Page 2 of 6

the maximum measured ES/ $\mathrm{ET}_{\mathrm{o}}$ often exceeded 1.2, which contrasts with findings by Snyder [2], who found that maximum ES/ $\mathrm{ET}_{\mathrm{o}}$ measurements following soil wetting ranged from 0.8 to 1.0 in Imperial Valley, California [17]. The Snyder [2] model was incorporated into the California Simulation of Evapotranspiration of Applied Water (Cal-SIMETAW) model [19].

The Snyder [2] model was not developed, and therefore not tested, for soils with water content above $\theta_{\mathrm{DUL}}$ in any part of the profile during second stage (due to a shallow water table or poor drainage). The first objective of this study was to evaluate the potential use of Snyder [2] for soils with water content above $\theta_{\text {DUL }}$ in some parts of the profile during second stage. The second objective was to evaluate Ritchie [1] soil evaporation model and compare its performance with that of Snyder [2]. A lysimeter experiment was carried out to produce some data for such a study.

\section{Materials and Method}

The experiment was carried out at the University of Florida Indian River Research and Education Center ( $\mathrm{Lat}=27.43$, long=-80.4, elevation $=19 \mathrm{~m}$ ) in Fort Pierce, Florida in 2013. Two lysimeters constructed from commercially available polyethylene tanks were used in this study to test and compare the performance of the two soil evaporation models. The tanks were $2.1 \mathrm{~m}$ in diameter at the top and $1.8 \mathrm{~m}$ in diameter at the bottom, by $0.76 \mathrm{~m}$ deep. A drain sump was made in the middle of the bottom of the lysimeter by drilling a $20 \mathrm{~mm}$ hole, installing a 200 mesh stainless screen, sealing with silicone, and bolting a bulkhead adapter through the bottom of the tank. A $20 \mathrm{~mm}$ $\mathrm{PE}$ tube was installed into the bulkhead adapter to control the removal of drainage water. The two lysimeters filled with sand (Bulk density $=1.47 \mathrm{~g} / \mathrm{cm}^{3}$, sand content more than $95 \%$, and $\theta_{\text {DUL }}=0.11 \mathrm{~cm}^{3} /$ $\mathrm{cm}^{3}$ ) uniformly without layering in November 2012. Before the sand was added, a $10 \mathrm{~cm}$ layer of gravel placed in the bottom of the tanks to facilitate drainage.

Eight Time-Domain Transmissometry (TDT) (Model Number: ACC-SEN-TDT, Acclima Inc., Idaho) probes were installed horizontally at depths of $3,6,9,12,15,25,35$ and $45 \mathrm{~cm}$ from the surface in December 2012. Hourly soil water content was monitored at these depths for six months after the installation for only one of the lysimeters because some of the sensors of the other lysismeter did not work properly. The 8 sensors were connected to a Data Snap (Acclima data logger, Model Number: ACC-AGR-D01) to control and store the soil moisture readings. The TDT sensor propagates the electromagnetic wave from a transmitter directly to a receiver at the distal end of the transmission line. The soil was saturated twice by leaving ponding water on the soil surface for 48 hours. The first saturation of the lysimeter took place on March 11, 2013 while the second was on April 7, 2013. Drainage of the lysimeter started on March 13, 2013 at 8:00 am after the excess water above the soil surface was first drained off. The drainage occurred for two days while the soil surface was covered. The soil water content measured following March 15 for seven days and was considered as the first drying period (Case 1). On April 1, the two lysimeters were covered to prevent soil water evaporation during drainage.

Drainage of the lysimeters started on April 9, 2013 at 8:00 am after the excess water above the soil surface was drained. On April 11 and 12 , a suction pump was used to drain as much water as possible of the lysimeters. On April 16, 2013, the lysimeters were uncovered (Case 2) and monitored the second drying cycle for six days. After 4 days of rain (April 19 to 22, 2013), a drying cycle of seven days (Case 3) took place.

Weather data was obtained from The Florida Automated Weather Network (FAWN) which provides up-to-date weather information through a system of automated weather stations distributed across Florida [20]. Air temperature, relative humidity, solar radiation and wind speed were downloaded from Fort Pierce weather station. The water balance approach was used to compute the actual daily soil evaporation. The measured daily drainage was assumed 0 because the drainage pipe was closed during evaporation.

\section{Model Description}

\section{Snyder et al. (2000) model}

The value of the potential soil evaporation, $E_{X}$, at any given time is given by

$$
\mathrm{E}_{\mathrm{X}}=\mathrm{K}_{\mathrm{X}} \mathrm{ET}_{\mathrm{o}}(1)
$$

where $\mathrm{K}_{\mathrm{X}}$ is maximum (potential) crop coefficient value for the bare soil under known $\mathrm{ET}_{\mathrm{o}}$ conditions.

The cumulative potential soil evaporation, $\mathrm{CE}_{\mathrm{X}}$, is given by

$$
\mathrm{CE}_{\mathrm{X}}=\mathrm{K}_{\mathrm{X}} \mathrm{CET}_{\mathrm{o}}(2)
$$

Soil hydraulic factor $\beta\left(\mathrm{mm}^{0.5}\right)$ defines the point of change from Stage 1 to Stage 2 and the evaporation rate during Stage 2.

When $\sqrt{ } C_{X}<\beta$, stage 1 is assumed, the cumulative soil evaporation, $\mathrm{CE}_{S}$, can be obtained as:

$$
\mathrm{CE}_{\mathrm{S}}=\mathrm{CE}_{\mathrm{X}}(3)
$$

During stage $2, \sqrt{ } \mathrm{CE}_{\mathrm{X}} \geq \beta, \mathrm{CE}_{S}$ is as follows:

$$
\mathrm{CE}_{\mathrm{S}}=\beta \sqrt{ } \mathrm{CE}_{\mathrm{X}}(4)
$$

The $\beta$ factor is determined using measured soil evaporation $E_{S}$ by plotting cumulative soil evaporation $\mathrm{CE}_{\mathrm{S}}$ versus the square root of the maximum possible (potential) cumulative soil evaporation $\mathrm{CE}_{\mathrm{X}}$.

\section{Ritchie et al. (2009) model}

Suleiman and Ritchie [12] derived the following equation from the diffusion theory for soils initially with water content equal or below $\theta_{\text {DUL }}$ throughout the soil profile.

$$
\Delta \theta=\mathrm{F}\left(\theta_{\mathrm{i}}-\theta_{\mathrm{ad}}\right)(5)
$$

Where $\theta_{\mathrm{i}}$ and $\theta_{\mathrm{ad}}$ are initial and air dry soil water content, respectively and $\mathrm{F}$ is the upward flow coefficient and can be obtained as follows:

$$
\mathrm{F}_{\mathrm{Z}}=\mathrm{a}_{\mathrm{z}} \mathrm{Z}_{\mathrm{z}}^{\mathrm{b}}(6)
$$

The $\mathrm{a}_{\mathrm{z}}$ and $\mathrm{b}_{\mathrm{z}}$ are empirical coefficients at depth $\mathrm{z}$.

The wet soil profile transfer coefficients are computed using $\mathrm{a}_{\mathrm{z}}=$ 0.26 and $b_{z}=-0.70$ when any soil layer in the top $100 \mathrm{~cm}$ has a water content above $\theta_{\text {DUL }}$ and the top soil layer is wetter than a threshold value, which is $\theta_{\mathrm{eq}}$ and computed as follows:

$$
\theta_{\mathrm{eq}}=0.275 \theta_{\mathrm{DULz}}+1.165\left(\theta_{\mathrm{DULz}}\right)^{2}+1.2 \mathrm{z}\left(\theta_{\mathrm{DULz}}\right)^{3.75}(7)
$$

The equilibrium transfer coefficient, $\mathrm{F}_{\mathrm{Z}}=0.011$, is used when the soil profile is wet, but the top layer is dryer than the threshold value. 


\section{Results}

Global The measured four-day average of Ritchie [1] upward flow coefficient, $\mathrm{F}_{\mathrm{Z}}$, at the first four soil depths $(3,6,9$ and $12 \mathrm{~cm})$ for Case 1 was greater than Case 2 and lower than Case 3 Figure 1. This indicated that $\mathrm{F}$ is somewhat dependent on the initial soil water content which was higher for these soil depths in Case 3 than Case 1 which was greater than Case 2. The measured four-day average upward flow coefficient in Case 1 was close to the estimated $\mathrm{F}_{\mathrm{Z}}$ using Equation [6] except for the first soil depth $(3 \mathrm{~cm})$ where the measured was about half of the estimated. For Cases 2 and 3, the measured four-day average upward flow coefficient was close to the estimated $\mathrm{F}_{\mathrm{Z}}$ for five soil depths and different at the other three soil depths, including the first soil depth. It was evident that the measured four-day average depended on the soil depth as suggested by Ritchie [1].

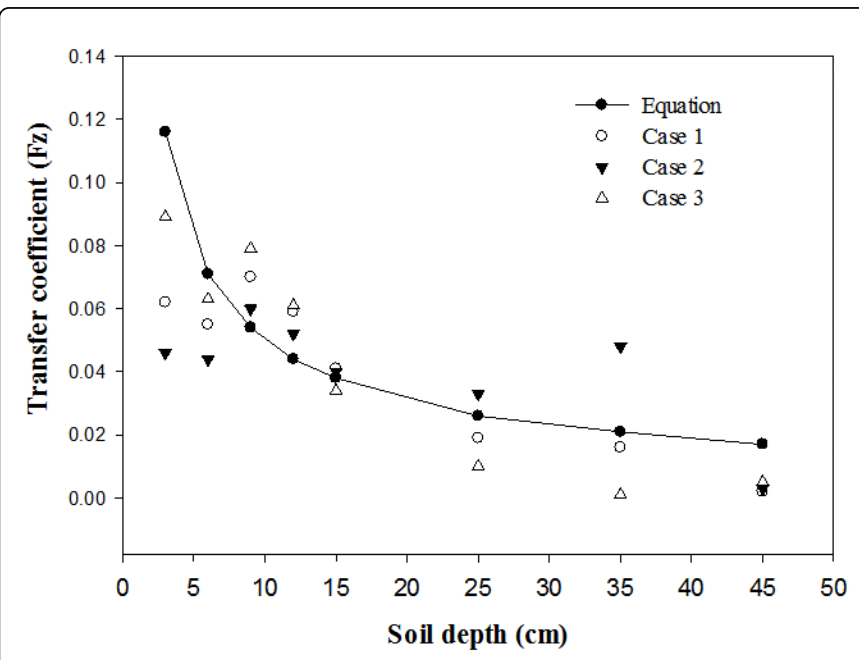

Figure 1: The Ritchie [1] transfer coefficient for the three cases.

The measured volumetric soil water content ranged from about 9 to $40 \%$ for Case 1,7 to $38 \%$ for Case 2, and 10 to $38 \%$ for Case 3 Figures 2-4. Ritchie [1] underestimated the soil water content at 3, 6 and $45 \mathrm{~cm}$ depths for Case 1, while for the other depths it performed relatively well. For Case 2, Ritchie [1] underestimated the soil water content at all depths except 25 and $35 \mathrm{~cm}$, where it was close to the measured values. For the first four days at all the soil depths except 9 and $12 \mathrm{~cm}$, Ritchie [1] estimated the soil water content relatively well in Case 3, and then tended to underestimate for the rest of the days. For soil depths of 9 and $12 \mathrm{~cm}$ in Case 3, Ritchie [1] overestimated the soil water content.
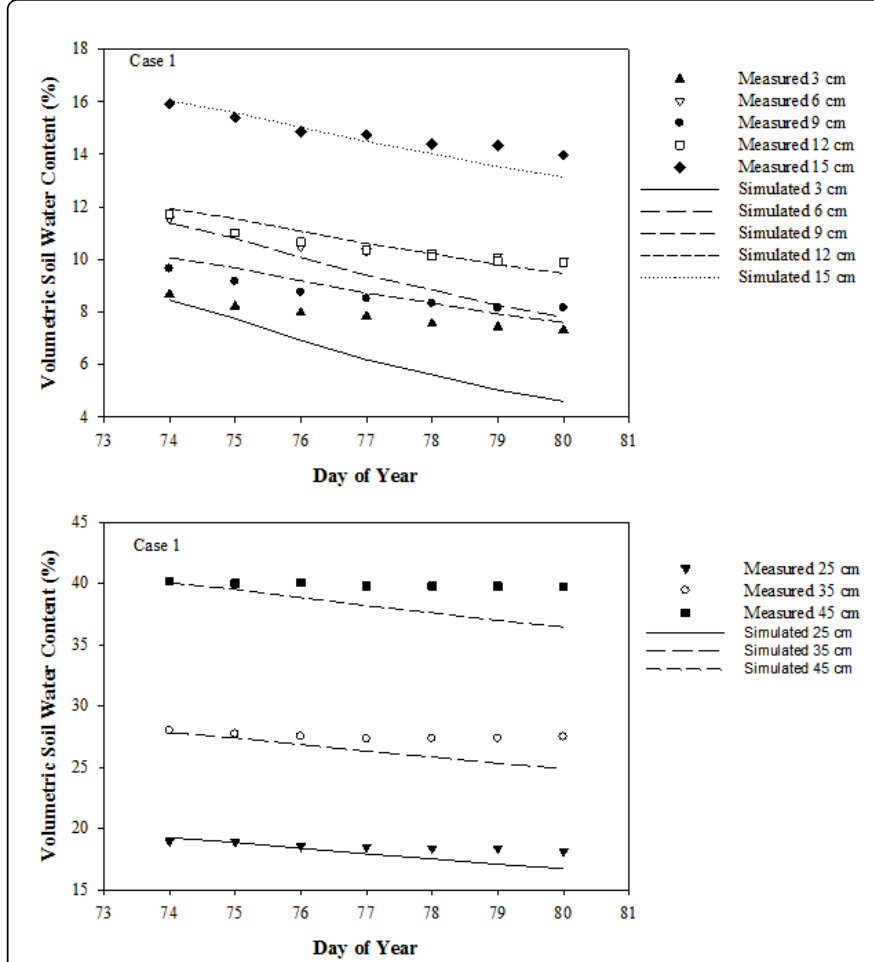

Figure 2: Soil water content for Case 1.

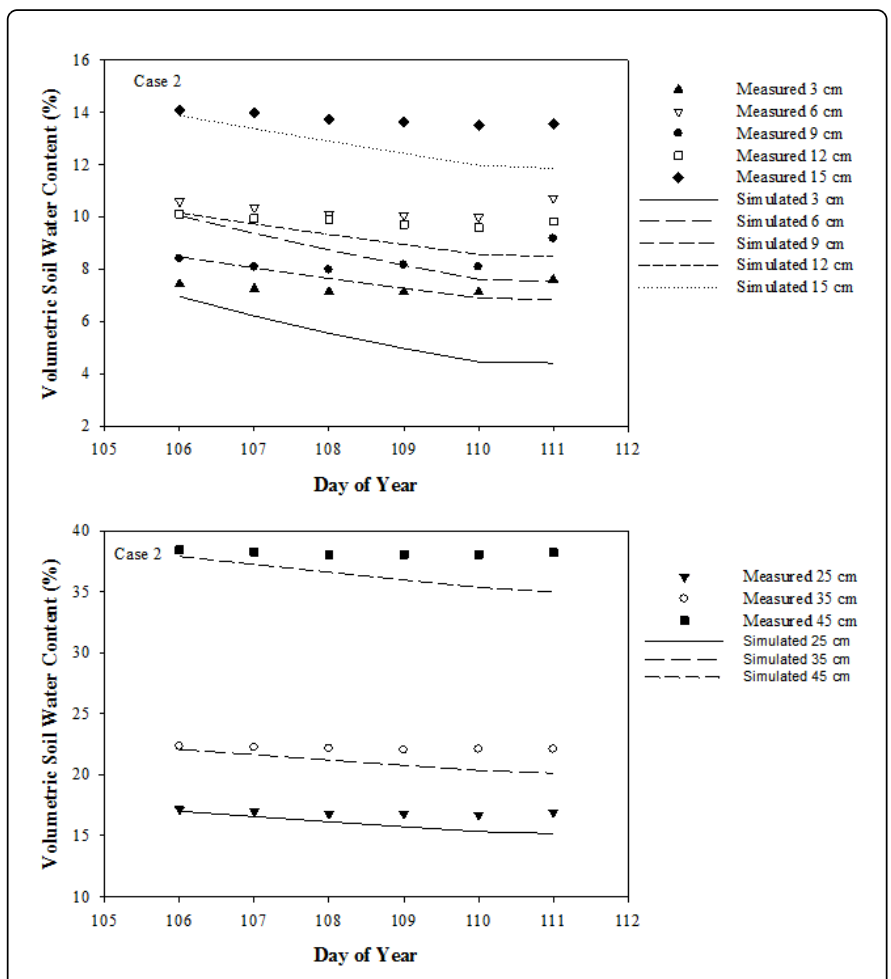

Figure 3: Soil water content for Case 2. 
Page 4 of 6

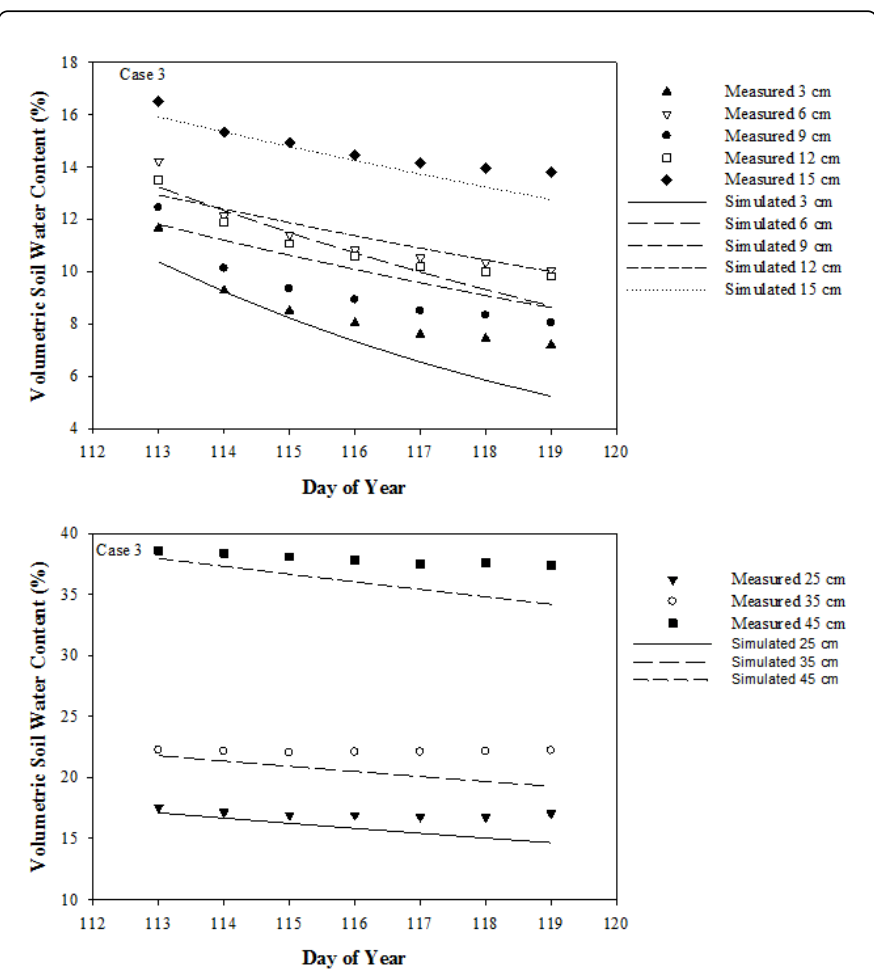

Figure 4: Soil water content for Case 3.

The maximum crop coefficient, $\mathrm{K}_{\mathrm{X}}$, value for Cases 1 and 3 were somewhat similar while for Case 2 it was about one third of that for Case 1 or Case 3 Table 1 . Case 1 and 2 had higher initial soil water content than Case 2, where a suction pump was used and drained more water from the lysimeter before the soil was uncovered. The maximum crop coefficient value for Cases 1 and 3 were lower than that documented by Snyder [2] because the soil in the lysimeter for those two cases was allowed to drain for 2 days before uncovering the soil surface, resulting in lower initial water content than those in the other studies.

\begin{tabular}{|l|l|l|l|l|}
\hline Case & DOY & $K_{x}$ & $\beta$ & \multirow{2}{*}{$R^{2+}$} \\
\cline { 4 - 4 } & & & $\left(\mathrm{mm}^{0.5}\right)$ & \\
\hline 1 & 74 & 0.62 & 2.81 & 0.98 \\
\hline 2 & 105 & 0.24 & 2.64 & 0.85 \\
\hline 3 & 113 & 0.66 & 4.05 & 0.96 \\
\hline
\end{tabular}

Table 1: Snyder [2] model parameters for the three cases.

\section{+ This $R^{2}$ is for $\beta$}

The maximum crop coefficient and soil hydraulic factor for Cases 1 and 3 were used to compute the soil evaporation for the three cases to find out which combination gave better estimates. The measured ES $\left(E S_{m}\right)$ rate of Cases 1 and 3 for the first three days was higher than Case 2, which had lower initial soil water content Figure 5. For Cases 1 and 3, Ritchie [1] ES $\left(\mathrm{ES}_{\mathrm{R}}\right)$ rate was close to $\mathrm{ES}_{\mathrm{m}}$ rate for the first two days, after which it consistently overestimated $\mathrm{ES}$ rate. In Case 2, $\mathrm{ES}_{\mathrm{R}}$ rate was greater than $\mathrm{ES}_{\mathrm{m}}$ rate for all days. The two combinations of Snyder [2] ES rate $\left(\mathrm{ES}_{\mathrm{S} 0.66,4.05}\right.$ and $\left.\mathrm{ES}_{\mathrm{S} 0.62,2.81}\right)$ were close to each other in Cases 1 and 2 while $\mathrm{ES}_{\mathrm{S} 0.62,2.81}$ outperformed $\mathrm{ES}_{\mathrm{S} 0.66,4.05}$ in Case 3. For the first three days in Case 1 and the two days in Case 3, $\mathrm{ES}_{\mathrm{R}}$ rate surpassed $\mathrm{ES}_{\mathrm{S} 0.66,4.05}$ and $\mathrm{ES}_{\mathrm{S} 0.62,2.81}$, while during the later days $\mathrm{ES}_{\mathrm{S} 0.66,4.05}$ and $\mathrm{ES}_{\mathrm{S} 0.62,2.81}$ were closer than $\mathrm{ES}_{\mathrm{R}}$ rate.
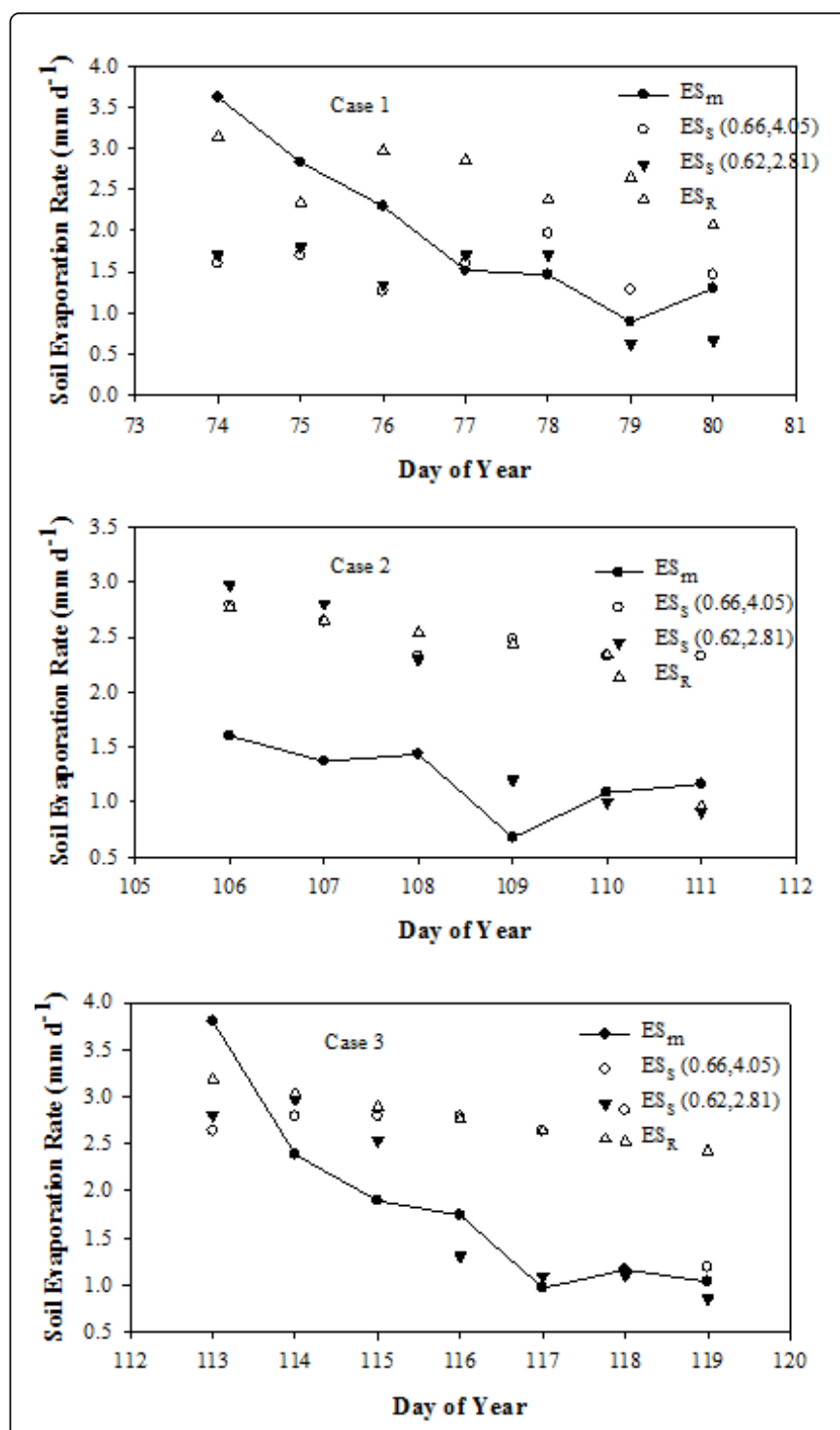

Figure 5: Soil evaporation rate for the three cases.

The $\mathrm{ES}_{\mathrm{m}}$ rate ranged from 0.9 to $3.6,0.7$ to 1.6 and 1 to $3.8 \mathrm{~mm} \mathrm{~d}^{-1}$ for Cases 1, 2, and 3, respectively Table 2. It is apparent that the lower initial soil water content in Case 2 resulted in a smaller maximum $\mathrm{ES}_{\mathrm{m}}$ rate. Although the minimum $E S_{R}$ rate was close to the minimum $\mathrm{ES}_{\mathrm{m}}$ rate, the minimum $E S_{R}$ rate was more than double the minimum $\mathrm{ES}_{\mathrm{m}}$ rate in the other cases. The reason is that in Case 2, the surface soil water content after a few days researched the threshold value and the equilibrium transfer coefficient was used. However in Cases 1 and 3, the surface soil water content did not research this threshold value. The minimum $\mathrm{ES}_{\mathrm{S} 0.66,4.05}$ rate was close to the minimum $\mathrm{ES}_{\mathrm{m}}$ rate for Case 1 and more than double in Cases 2 and 3. It is interesting that the minimum $\mathrm{ES}_{\mathrm{S} 0.62,2.81}$ rate was close to the minimum $\mathrm{ES}_{\mathrm{m}}$ rate for all 
Citation: Ayman Suleiman and Brian Boman (2014) Comparison of Two Soil Water Evaporation Models in a Sandy Soil. Irrigat Drainage Sys

Page 5 of 6

the cases. The maximum $\mathrm{ES}_{\mathrm{R}}$ rate was closer to the maximum $\mathrm{ES}_{\mathrm{m}}$ rate than that of $\mathrm{ES}_{\mathrm{S} 0.66,4.05}$ and $\mathrm{ES}_{\mathrm{S} 0.62,2.81}$ for Cases 1and 3. In all the cases, the maximum $\mathrm{ES}_{\mathrm{S} 0.66,4.05}$ and $\mathrm{ES}_{\mathrm{S} 0.62,2.81}$ were similar. The mean $\mathrm{ES}_{\mathrm{R}}$ rate was about 30,85 and $50 \%$ greater than the mean $\mathrm{ES}_{\mathrm{m}}$ rate for Cases 1, 2 and 3, respectively. The mean $\mathrm{ES}_{\mathrm{S} 0.66,4.05}$ rate was about $20 \%$ lower than the mean $\mathrm{ES}_{\mathrm{m}}$ rate for Case 1, and 100 and $35 \%$ greater for Cases 2 and 3, respectively. The mean $\mathrm{ES}_{\mathrm{S} 0.62,2.81}$ rate was about $30 \%$ lower than the mean $\mathrm{ES}_{\mathrm{m}}$ rate for Case 1,50\% greater for Case 2, and almost identical for Case 3. The root man square error (RMSE) was close between $\mathrm{ES}_{\mathrm{R}}$ rate and $\mathrm{ES}_{\mathrm{S} 0.66,4.05}$ for all the cases, while it was lower for $\mathrm{ES}_{\mathrm{S} 0.62,2.81}$ for the three cases, especially for Case 3.

\begin{tabular}{|c|c|c|c|}
\hline Parameter & Case 1 & Case 2 & Case 3 \\
\hline \multicolumn{4}{|c|}{ Minimum rate $\left(\mathrm{mm} \mathrm{d}^{-1}\right)$} \\
\hline $\mathbf{E S}_{\mathrm{m}}$ & 0.89 & 0.68 & 0.97 \\
\hline $\mathrm{ES}_{\mathrm{R}}$ & 2.06 & 0.96 & 2.42 \\
\hline ES $_{\mathbf{S} 0.66,4.05}$ & 1.26 & 2.33 & 1.99 \\
\hline $\mathrm{ES}_{\mathrm{S} 0.62,2.81}$ & 0.63 & 0.91 & 0.85 \\
\hline \multicolumn{4}{|c|}{ Maximum rate $\left(\mathrm{mm} \mathrm{d}^{-1}\right)$} \\
\hline $\mathbf{E S}_{\mathrm{m}}$ & 3.61 & 1.6 & 3.8 \\
\hline $\mathrm{ES}_{\mathrm{R}}$ & 3.14 & 2.77 & 3.19 \\
\hline $\mathbf{E S}_{\mathrm{S} 0.66,4.05}$ & 1.96 & 2.79 & 2.85 \\
\hline $\mathrm{ES}_{\mathrm{S} 0.62,2.81}$ & 1.8 & 2.97 & 2.97 \\
\hline \multicolumn{4}{|c|}{ Mean rate $\left(\mathrm{mm} \mathrm{d}^{-1}\right)$} \\
\hline $\mathbf{E S}_{\mathrm{m}}$ & 1.99 & 1.22 & 1.86 \\
\hline $\mathbf{E S}_{\mathrm{R}}$ & 2.62 & 2.28 & 2.78 \\
\hline $\mathrm{ES}_{\mathrm{S} 0.66,4.05}$ & 1.55 & 2.48 & 2.53 \\
\hline $\mathrm{ES}_{\mathrm{S} 0.62,2.81}$ & 1.36 & 1.86 & 1.81 \\
\hline \multicolumn{4}{|c|}{$\operatorname{RMSE}\left(\mathrm{mm} \mathrm{d}^{-1}\right)$} \\
\hline $\mathbf{E S}_{\mathrm{R}}$ & 1.01 & 1.22 & 1.16 \\
\hline $\mathrm{ES}_{\mathrm{S} 0.66,4.05}$ & 0.99 & 1.29 & 1.14 \\
\hline $\mathbf{E S}_{\mathrm{S} 0.62,2.81}$ & 0.94 & 0.91 & 0.53 \\
\hline
\end{tabular}

Table 2: Summary statistics of soil evaporation

The cumulative $\mathrm{ES}_{\mathrm{m}}$ at the end of each period in Cases 1 and 3 was about double that in Case 2 Figure 6. For Cases 1 and 3, the cumulative $E S_{R}$ was close to that of $E S_{m}$ until the fourth day, after which the difference between $\mathrm{ES}_{\mathrm{R}}$ and $\mathrm{ES}_{\mathrm{m}}$ was increasing. For Case 2, the difference between $\mathrm{ES}_{\mathrm{R}}$ and $E S_{\mathrm{m}}$ increased from the first day. For Case 1, the cumulative $\mathrm{ES}_{\mathrm{S} 0.66,4.05}$ and $\mathrm{ES}_{\mathrm{S} 0.62,2.81}$ were similar and underestimated the cumulative $\mathrm{ES}_{\mathrm{m}}$. The cumulative $\mathrm{ES}_{\mathrm{S} 0.66,4.05}$ was close to the cumulative $\mathrm{ES}_{\mathrm{R}}$, overestimating for all the days. In contrast, the cumulative $\mathrm{ES}_{\mathrm{S0.62,2.81}}$ was close to the cumulative $\mathrm{ES}_{\mathrm{R}}$ only for the 4 days in Case 2, while on the other days the cumulative $\mathrm{ES}_{\mathrm{S} 0.62,2.81}$ was higher than the cumulative $\mathrm{ES}_{\mathrm{m}}$ and lower than the cumulative $\mathrm{ES}_{\mathrm{R}}$. The cumulative $\mathrm{ES}_{\mathrm{R}}$ and $\mathrm{ES}_{\mathrm{S} 0.66,4.05}$ were alike for all the days and they were close to that of $E S_{m}$ for the first four days, after which they overestimated the cumulative ES in Case 3. The cumulative $\mathrm{ES}_{\mathrm{S} 0.62,2.81}$ and $\mathrm{ES}_{\mathrm{m}}$ were identical throughout Case 3.
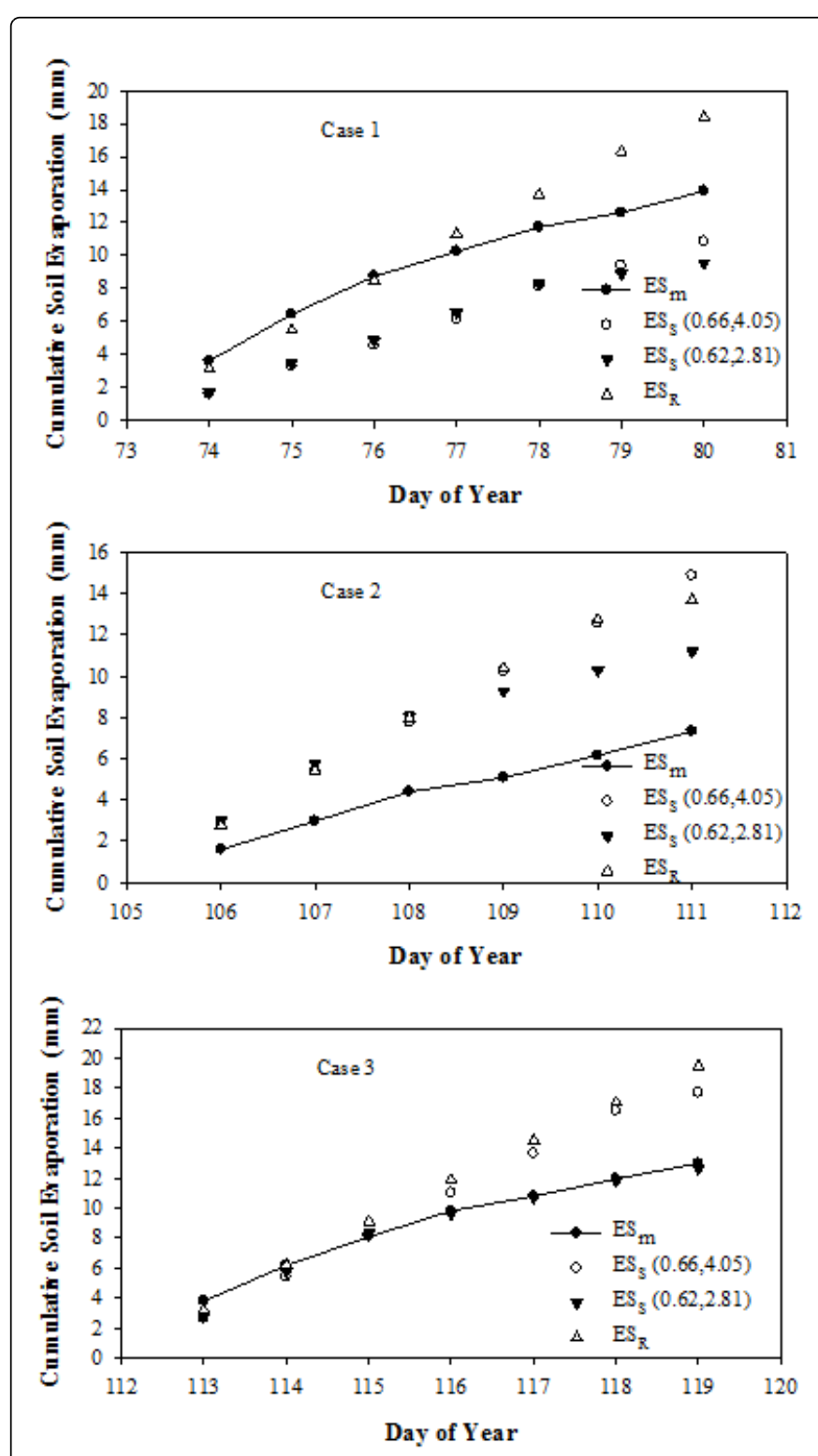

Figure 6: Cumulative soil evaporation for the three cases.

\section{Conclusions}

An experiment was conducted on a lysimeter filled with a sandy soil to evaluate Ritchie and Snyder [1,2] to for soils with water content above $\theta_{\text {DUL }}$ in some parts of the profile. The Ritchie [1] upward flow coefficient, F, was dependent on soil depth as suggested by Ritchie [1] and somewhat dependent on the initial soil water. For the soil depths ( 3 to $15 \mathrm{~cm}$ ) that have the most significant impact on soil evaporation, the estimated four-day average upward flow coefficient for the three cases was close to the measured F except for the first soil depth $(3 \mathrm{~cm})$ where the estimated was much higher than the measured especially for case 1 and 2. The results of this study confirmed that Snyder [2] with a proper parameterization can be successfully used to model ES for wet 
soil profile and it outperformed Ritchie [1] model. The Snyder [2] soil hydraulic factor, $\beta$, was depend on the near surface soil water content than the deeper ones. Although, the deeper soil water content was above $\theta_{\text {DUL }}$ in all three cases, the range of soil hydraulic factor was similar to that reported in Snyder [2]. It was evident that getting the suitable parameterization of Snyder [2] model is not always guaranteed. Although, the performance of Ritchie [1] in simulating the soil water content varied from one case to another, it generally underestimated the soil water content near the surface. The root man square error (RMSE) was close between $\mathrm{ES}_{\mathrm{R}}$ rate and $\mathrm{ES}_{\mathrm{S} 0.66,4.05}$ for all the cases, while it was lower for $\mathrm{ES}_{\mathrm{S} 0.62,2.81}$ for the three cases, especially for Case 3 .These finding may only apply for coarse-textured soils similar to the one used in this study. Other studies need to be carried out for different soils and different environment before generalization can be made.

\section{Acknowledgments}

The authors extend their deep thanks to Mr. Jerry Britt for his help with setting up the experiment. The research for this article was done while the first author on Sabbatical Leave at the University of Florida Indian River Research and Education Center.

\section{References}

1. Ritchie JT, Porter CH, Judge J, Jones JW, Suleiman AA (2009) Extension of an existing model for soil water evaporation and redistribution under high water content conditions. Soil Sci Soc Am J 73: 792-801.

2. Snyder R, Bali K, Ventura F, Gomez-MacPherson H (2000) Estimating Evaporation from Bare or Nearly Bare Soil. J Irrig Drain Eng 126: 399-403.

3. Brutsaert W (1982) Evaporation into the Atmosphere Theory, History and Applications. Environmental Fluid Mechanics 1.

4. Ritchie JT (1972) Model for predicting evaporation from a row crop with incomplete cover. Water Resour Res 8: 1204-1213.

5. Philip JR, De Vries DA (1957) Moisture movement in porous materials under temperature gradients. Transactions American Geophysical Union 38: $222-232$.
6. Jackson RD, Reginato RJ, Kimball BA, Nakayama FS (1974) Diurnal soilwater evaporation: Comparison of measured and calculated soil-water fluxes. Soil Sci Soc Am J 38: 861-866.

7. Rose CW (1968a) Evaporation from bare soil under high radiation conditions. Transactions International Society of Soil Science 1: 57-66.

8. Rose DA (1968b) Water movement in porous materials III. Evaporation of water from soil. J Phys D Appl Phys 1: 1779-1791.

9. Lascano RJ, Bavel CHM (1983) Experimental verification of a model to predict soil moisture and temperature profiles. Soil Sci Soc Am J 47: 441-448.

10. Lascano RJ, Bavel CHM (1986) Simulation and measurement of evaporation from a bare soil. Soil Sci Soc Am J 50: 1127-1133.

11. Black TA, Gardner WR, Thurtell GW (1969) The prediction of evaporation, drainage, and soil water storage for a bare soil. Soil Sci Soc Am J 33: 655-660.

12. Suleiman AA, Ritchie JT (2003) Modeling soil water redistribution during second-stage evaporation. Soil Sci Soc Am J 67: 377-386.

13. Tsuji GY, Hoogenboom G, THornton PK (1998) Systems Approaches for Sustainable Agricultural Development Understanding options for agricultural production. Kluwer Academic Publishers USA.

14. Allen RG, Pereira LS, Smith M, Raes D, Wright JL (2005a) FAO-56 Dual crop coefficient method for estimating evaporation from soil and application extensions. J Irrig Drain Eng 131: 2-13.

15. Allen RG, Pruitt WO, Raes D, Smith M, Pereira LS (2005b) Estimating evaporation from bare soil and the crop coefficient for the initial period using common soils information. J Irrig Drain Eng 131: 14-23.

16. Torres EA, Calera A (2010) Bare soil evaporation under high evaporation demand: a proposed modification to the FAO-56 model. HYDROLOG SCI J 55: 303-315.

17. Mutziger A, Burt C, Howes D, Allen R (2005) Comparison of Measured and FAO-56 Modeled Evaporation from Bare Soil. J Irrig Drain Eng 131: 59-72.

18. Ventura F, Snyder R, Bali K (2006) Estimating Evaporation from Bare Soil Using Soil Moisture Data. J Irrig Drain Eng 132: 153-158.

19. Orang MN, Snyder RL, Shu G, Hart QJ, Sarreshteh S, et al. (2013) California Simulation of Evapotranspiration of Applied Water and Agricultural Energy Use in California. Journal of Integrative Agriculture 12: 1371-1388.

20. http://fawn.ifas.ufl.edu/ 